\title{
EFFECT ON BLENDING OF SUPPLEMENTARY CEMENTITIOUS MATERIALS ON PERFORMANCE OF NORMAL STRENGTH CONCRETE
}

\author{
S. JAGAN \\ Department of Civil Engineering, Kalasalingam Academy of Research and Education, Anand Nagar 626 126, India
}

\begin{abstract}
Sustainability and scarcity in resources are the two major issues to be dealt within the present scenario by effective utilization of alternative materials. In this present study, an attempt has been taken to study the effect of supplementary materials such as fly ash and silica fume as a partial replacement to cement and steel slag and M-sand as a replacement to river sand on strength and durability of concrete. In this study, concrete specimens were prepared based on five different mixes by varying the percentages of these supplementary materials. Various mechanical properties like compressive strength, split tensile strength and flexural strength were performed to ascertain the mix with optimum levels of replacement of supplementary materials for cement and fine aggregate. Durability property like water absorption test was performed on the mix with optimum values of strength. Results revealed that mix with higher percentages of steel slag, optimum level of silica fume and fly ash have shown higher strength and lesser permeability in concrete.
\end{abstract}

Keywords: sustainability, scarcity, permeability, M-sand, silica fume, fly ash and steel slag

\section{Introduction}

Sustainability has also become an important area of study in the field of construction nowadays due to scarcity in construction materials and depletion of the global environment. Usage of alternative materials such as waste from industries, recycling the materials, etc., would be an optimal solution to achieve the sustainability in construction. Various researches have been performed in and around the globe mainly focussing on the mineral admixtures such as fly ash, steel slag, ground granulated blast furnace slag (GGBS), $\mathrm{M}$-sand, etc., as a partial or complete replacement to cement and aggregates. For instance, partial replacement of cement by steel slag and blast furnace slag powder has shown better mechanical properties when compared to conventional concrete [1]. Also the rate of $\mathrm{CO}_{2}$ emission also gets reduced by partial replacement with cement, which shows a better indication for achieving the sustainable concrete. One of the major drawbacks in the use of steel slag in concrete is its higher porosity and also rusting property; it happens when it comes in contact with water due to its porous nature. Perhaps other commonly used pozzolanic materials like fly ash, a by-product from thermal power plants can be replaced by nominal percentage and as well by the higher percentage by weight of cement. Fly ash has the property of reacting at later stages when added to the concrete due to its pozzolanic activity. So concrete with fly ash at the curing of 90 days has yielded better mechanical properties when compared to conventional concrete [2]. In terms of its durability properties, fly ash replacement at $30 \%$ with lower w/c ratio by addition of water reducers has greater resistance to shrinkage [4]. But usage of higher fineness of fly ash reduces the slump loss as well as increases the mechanical property of concrete. This attribute is towards the pore filling ability of higher fineness fly ash in the concrete [6]. Despite increasing the operational cost in the manufacturing of higher fineness fly ash, usage of alternative material like silica fume would be an optimal solution. Addition of silica fume of fineness up to $30,000 \mathrm{~m}^{2} / \mathrm{kg}$ up to $10 \%$ had increased the strength of the concrete [3]. Such increase in strength of concrete by addition of silica fume is due to its higher fineness value which fills up

Open Access statement. This is an open-access article distributed under the terms of the Creative Commons AttributionNonCommercial 4.0 International License (https://creativecommons.org/licenses/by-nc/4.0/), which permits unrestricted use, distribution, and reproduction in any medium for non-commercial purposes, provided the original author and source are credited, a link to the CC License is provided, and changes - if any - are indicated. 
the voids, thereby improving the performance of concrete both in terms of strength and durability [2]. Not only the supplementary cementitious materials have a role in imparting the sustainability to concrete, but also due to a higher scarcity of river sand, M-sand can be a suitable alternative even up to $100 \%$ replacement. Usage of well graded M-sand with better particle packing up to $100 \%$ can improve the performance of concrete both in terms of strength and durability. Among various researches conducted on pozzolanic materials, these mineral additives can be replaced only up to certain percentages. The extent of research on blending the supplementary cementitious materials is very narrow. The present work mainly focuses on filling up such a research gap. The main objective of this research is to blend fly ash and silica fume with cement and $\mathrm{M}$-sand and steel slag with fine aggregate under different replacement levels to determine the optimum level of replacement of pozzolanic materials to achieve proper blending. To accomplish such objectives, five mix combinations with varying replacement percentages of fly ash, silica fume, steel slag and M-sand were prepared. Such mixes were tested for both strength and durability to evaluate their performance behaviour.

\section{Experimental programme}

\section{Materials}

Ordinary Portland cement of 53 grade IS: 8112-1989, river sand passing through $2.36 \mathrm{~mm}$ with fineness modulus 2.76, coarse aggregate, coarse aggregate of $20 \mathrm{~mm}$ with fineness modulus 6.73 , class F fly ash col- lected from Thoothukudi Thermal Power Plant, silica fume collected from locally available market, steel slag passing through $2.36 \mathrm{~mm}$ with fineness modulus 2.65, M-sand passing through $2.36 \mathrm{~mm}$ and water confirming to IS 456:2000 were used. Various properties of materials used in this study are presented in Table 1.

\section{Mix proportions}

M20 grade of concrete with w/c ratio of 0.5 was used in this study. A total of 96 specimens were prepared both control mix and mix with supplementary cementitious materials. Six different Mix combinations M0, M1, M2, M3, M4 and M5 were used in this study. M0 represents the control concrete mix of ratio $1: 1.5: 3$ having the characteristic compressive strength of 20 $\mathrm{MPa}$. Mix proportions for the mix M0 to M5 is presented in Table 2. The Quantity of materials required for the specified mix is presented in Table 3.

\section{Preparation of specimens}

Cubes of size $150 \mathrm{~mm} \times 150 \mathrm{~mm} \times 150 \mathrm{~mm}$, cylinders of size $100 \mathrm{~mm} \times 200 \mathrm{~mm}$ and prisms of size $500 \mathrm{~mm}$ $\times 100 \mathrm{~mm} \times 100 \mathrm{~mm}$ were prepared for this study. The coarse aggregates had been first poured into the mixer before half of the fine aggregates were added. The binder had been completely poured in, followed by the rest of the sand and collected supplementary cementitious materials based on the mix proportions. The machine had been then allowed to run for about one minute to ensure dry mixing of the ingredients before the calculated water was added. Water was then added immediately. After about three minutes of complete mix-

Table 1. Properties of concrete ingredients

\begin{tabular}{lllll}
\hline S. No & \multicolumn{1}{c}{ Material } & \multicolumn{1}{c}{ Properties } & \multicolumn{1}{c}{ Test method adopted } & \multicolumn{1}{c}{ Values } \\
\hline 1 & Cement & Surface area & Blain's air permeability & $225 \mathrm{~m}^{2} / \mathrm{kg}$ \\
\cline { 3 - 5 } & & Setting time & Vicat apparatus & Initial $=30 \mathrm{~min}$ \\
& & & Final $=600 \mathrm{~min}$ \\
\cline { 3 - 5 } & & Specific Gravity & Pycnometry & 3.15 \\
\hline 2 & River sand & Size & Sieve analysis & $2.36 \mathrm{~mm}$ \\
& & Fineness modulus & Sieve analysis & 2.76 \\
\hline 3 & Coarse aggregate & Size & Sieve analysis & $20 \mathrm{~mm}$ \\
& & Fineness modulus & Sieve analysis & 6.73 \\
\hline 4 & Fly ash & Surface area & Blain's air permeability & $296 \mathrm{~m} / \mathrm{kg}$ \\
& & Specific gravity & Pycnometry & 2.10 \\
\hline 5 & Silica fume & Surface area & Blain's air permeability & $28,000 \mathrm{~m} / \mathrm{kg}$ \\
& & Specific gravity & Pycnometry & 2.2 \\
\hline 6 & Steel slag & Surface area & Blain's air permeability & $350 \mathrm{~m}^{2} / \mathrm{kg}$ \\
& & Specific gravity & Pycnometry & 3.27 \\
\hline 7 & M-sand & Specific gravity & Pycnometry & 2.73 \\
\hline
\end{tabular}


Table 2. Mix proportions

\begin{tabular}{lcccccccc}
\hline Mix & Cement & F. A & S. F & R. S & M. S & S. S & C. A & w/c ratio \\
\hline M0 & 100 & - & - & 100 & - & - & 100 & 0.5 \\
M1 & 50 & 30 & 20 & - & 40 & 60 & 100 & 0.5 \\
M2 & 50 & 35 & 15 & - & 60 & 40 & 100 & 0.5 \\
M3 & 50 & 40 & 10 & - & 30 & 70 & 100 & 0.5 \\
M4 & 50 & 45 & 5 & - & 70 & 30 & 100 & 0.5 \\
M5 & 50 & 50 & - & - & 50 & 50 & 100 & 0.5 \\
\hline
\end{tabular}

F. A = Fly ash; $\mathrm{S} . \mathrm{F}=$ Silica fume; R. S = River sand; M. S = Manufactured sand; S. S = Steel slag;

C. $A=$ Coarse aggregate

Table 3. Quantity of proportioned materials

\begin{tabular}{llcccccc}
\hline Mix & $\begin{array}{l}\text { Cement } \\
\left(\mathrm{kg} / \mathrm{m}^{3}\right)\end{array}$ & $\begin{array}{c}\text { F. A } \\
\left(\mathrm{kg} / \mathrm{m}^{3}\right)\end{array}$ & $\begin{array}{c}\text { S. F } \\
\left(\mathrm{kg} / \mathrm{m}^{3}\right)\end{array}$ & $\begin{array}{c}\text { R. S } \\
\left(\mathrm{kg} / \mathrm{m}^{3}\right)\end{array}$ & $\begin{array}{c}\text { M. S } \\
\left(\mathrm{kg} / \mathrm{m}^{3}\right)\end{array}$ & $\begin{array}{c}\text { S. S } \\
\left(\mathrm{kg} / \mathrm{m}^{3}\right)\end{array}$ & $\begin{array}{c}\text { C. A } \\
\left(\mathrm{kg} / \mathrm{m}^{3}\right)\end{array}$ \\
\hline M0 & 383 & - & - & 727 & - & - & 1103 \\
M1 & 191.5 & 114.9 & 76.6 & - & 290.8 & 436.2 & 1103 \\
M2 & 191.5 & 134.05 & 57.45 & - & 436.2 & 290.8 & 1103 \\
M3 & 191.5 & 153.2 & 38.3 & - & 218.1 & 508.9 & 1103 \\
M4 & 191.5 & 172.35 & 19.15 & - & 508.9 & 218.1 & 1103 \\
M5 & 191.5 & 191.5 & - & - & 363.5 & 363.5 & 1103 \\
\hline
\end{tabular}

F. A = Fly ash; S. F = Silica fume; R. S = River sand; M. S = Manufactured sand; S. S = Steel slag;

C. $\mathrm{A}=$ Coarse aggregate

ing the machine was switched off. The concrete was placed in already prepared oiled moulds on the table vibrator. Placement of the concrete was carried out in three layers and the table vibrator was used to ensure adequate compaction of the concrete after each layer was placed. On completion of casting, the concrete-filled moulds were then transferred to the laboratory floor to set and harden for 24 hours. After 24 hours, demoulding of the specimens were carried out, the specimens were given identification marks and transformed to the curing tank for 28 days as required.

\section{Testing of prepared specimens}

Hardened properties like compressive strength, split tensile strength and flexural strength were performed on cube, cylinder and prism specimens as per IS 516:1959 to investigate the optimum level of re-

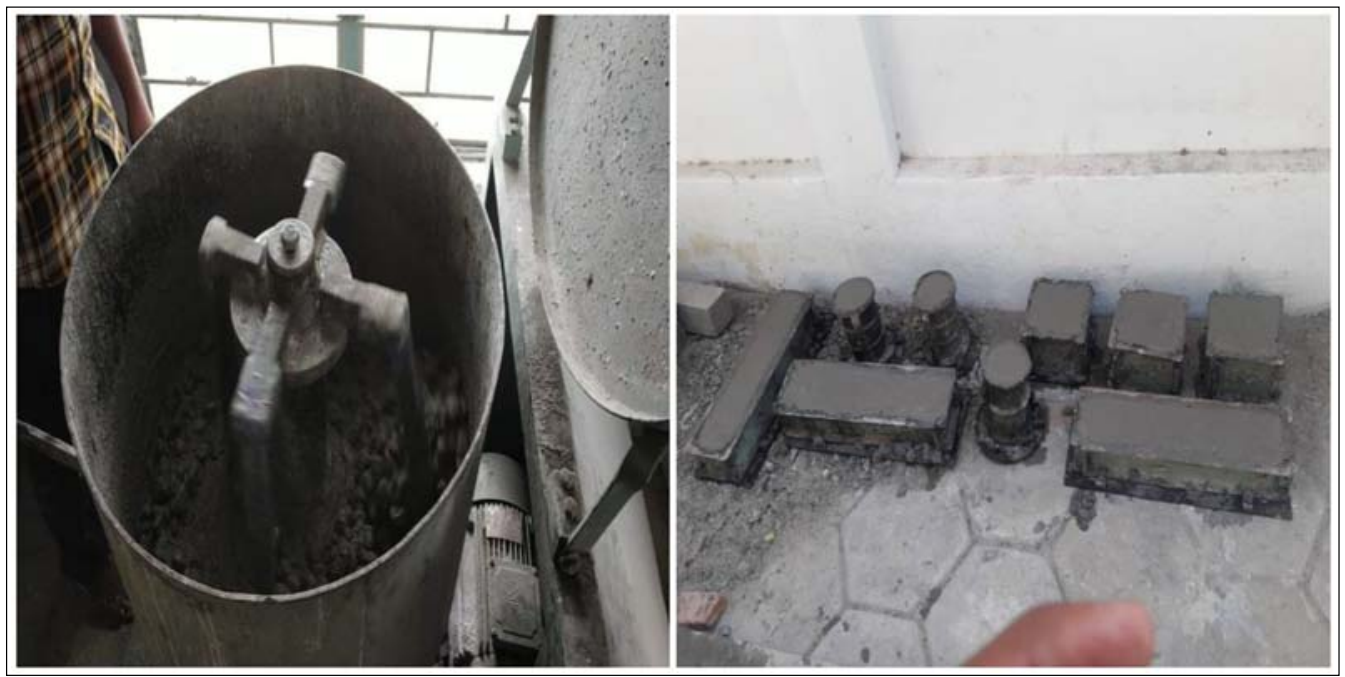

Fig. 1. Casting of concrete specimens 
placement of cementitious materials in concrete. Average of three specimens was taken as final reading under each test. Mix with optimum strength value determined from above tests was subjected to durability study like a sorptivity test to determine the rate of permeability of concrete.

\section{Results and discussion}

\section{Hardened properties}

From the test results it is evident that the M3 combination has values in terms of compressive strength, split tensile strength and flexural strength. M1 has the strength of $23.38 \%$, which is more than the strength of M0; M2 has the strength of $17.17 \%$, more than the strength of M0; M3 has the strength of $26.64 \%$, more than the strength of M0; M4 has the strength of $16.4 \%$, more than the strength of M0 and M5 has the strength of $13.7 \%$, more than the strength of M0. Similarly, the value shows the same increasing trends of strength in terms of both split tensile strength test and flexural strength test as it is evident from the values presented below. From the strength, it can be seen that M3 combination has $40 \%$ of fly ash as cement replacement and $70 \%$ of steel slag as fine aggregate replacement shown better strength of around $30 \%$ when compared to conventional concrete. Presence of steel slag at higher levels of replacement around $70 \%$ and fly ash of around $40 \%$ contributes towards the increase in the strength of concrete at the age of 28 days. Also it could be seen that at the age of 7 days, the expected strength for M3 is not achieved. This is because of the late reactivity of fly ash as the fly ash starts reacting only at the age of 28 days. This can also be evident from the fact that M5 has highest percentage of fly ash, which has the least strength value at the age of 28 days when compared to M1, M2, M3 and M4. Also, silica fume added around $10 \%$ plays a role in filling up the void spaces between the cement particles which also contributes towards the improvement in strength of concrete. From Table 1, it is clear that the size of mineral additives added as a replacement to cement and fine aggregate is nearly the same in order to achieve a uniform blending of raw materials. M-sand and steel slag passing through $2.36 \mathrm{~mm}$ sieve blends uniformly with each other provides better particle packing which contributes towards the improvement in strength of the concrete.

Table 4. Compressive strength at the age of 7 days and 28 days

\begin{tabular}{|c|c|c|c|c|c|c|c|}
\hline \multirow[t]{2}{*}{ S. No } & \multirow[t]{2}{*}{ Mix } & \multicolumn{2}{|c|}{ Compressive strength (MPa) } & \multicolumn{2}{|c|}{ Split tensile strength $(\mathrm{MPa})$} & \multicolumn{2}{|c|}{ Flexural strength $(\mathrm{MPa})$} \\
\hline & & 7 days & 28 days & 7 days & 28 days & 7 days & 28 days \\
\hline 1 & M0 & 14.51 & 21.67 & 1.74 & 2.6 & 2.66 & 3.25 \\
\hline 2 & M1 & 16.87 & 28.45 & 2.34 & 3.19 & 2.87 & 3.73 \\
\hline 3 & M2 & 15.97 & 26.17 & 1.84 & 3.04 & 2.79 & 3.58 \\
\hline 4 & M3 & 17.13 & 29.54 & 2.01 & 3.31 & 2.89 & 3.80 \\
\hline 5 & M4 & 15.13 & 25.93 & 1.80 & 3.02 & 2.72 & 3.56 \\
\hline 6 & M5 & 16.12 & 25.13 & 1.93 & 2.96 & 2.81 & 3.51 \\
\hline
\end{tabular}

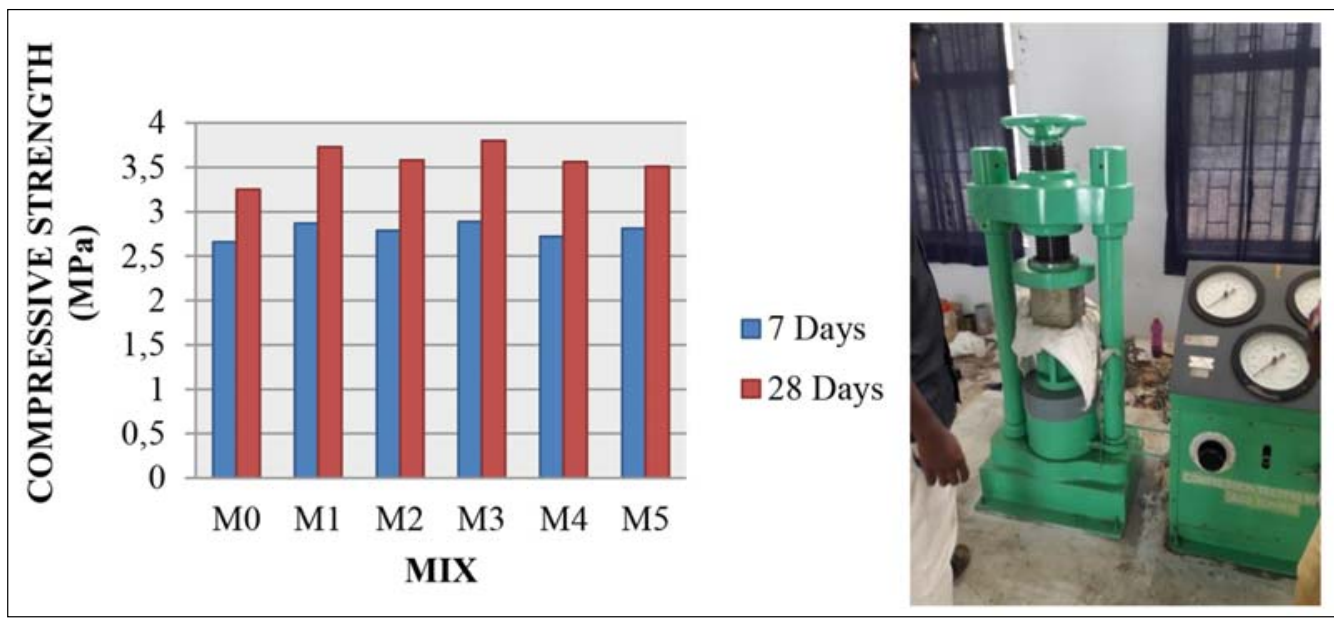

Fig. 2. Compressive strength at the age of 7 days and 28 days 


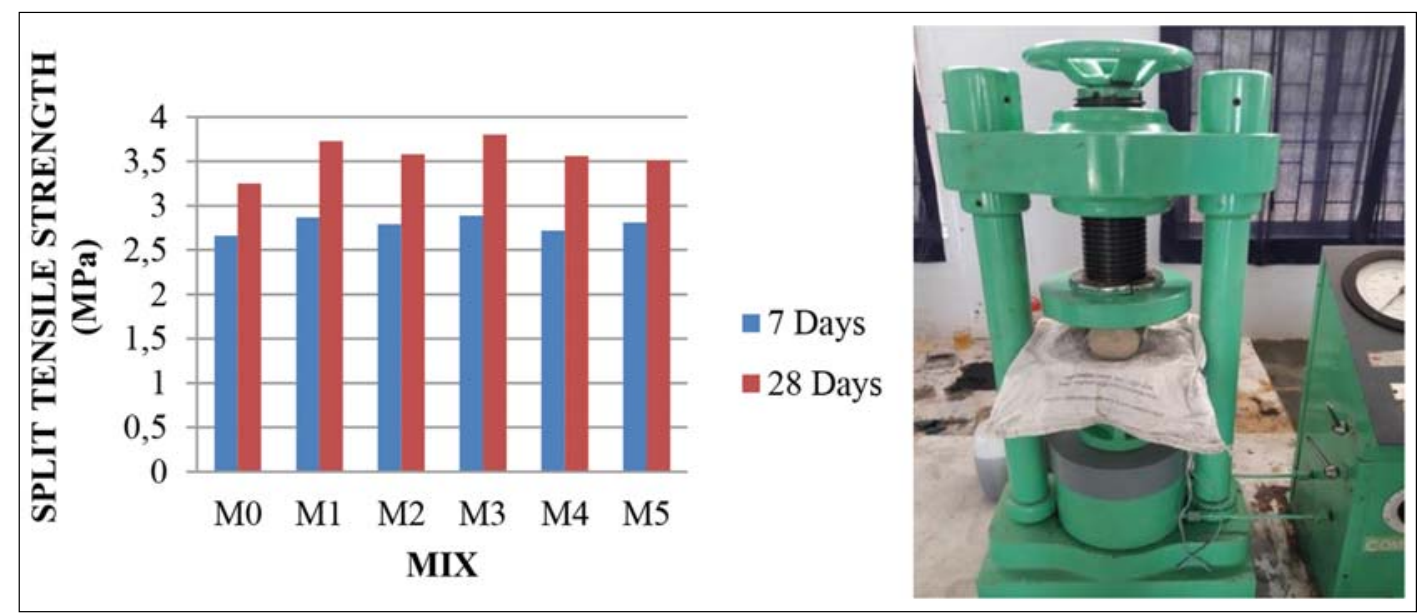

Fig. 3. Split tensile strength at the age of 7 days and 28 days

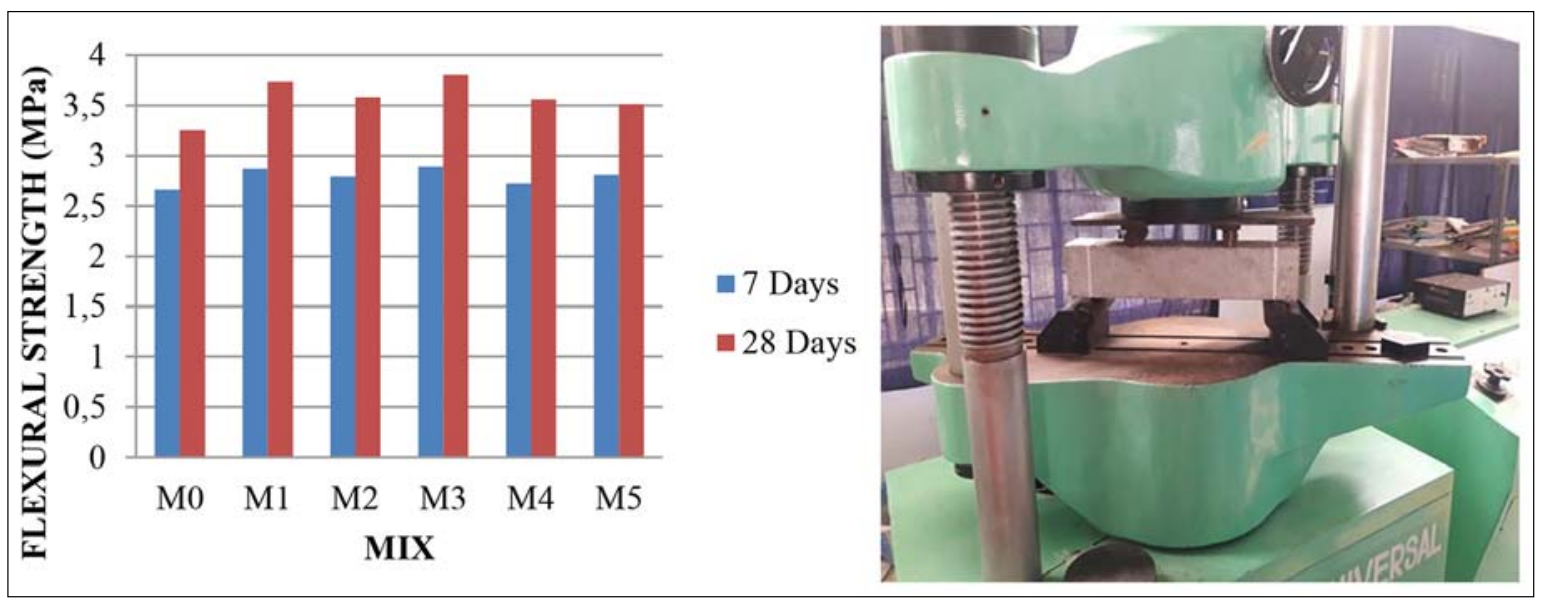

Fig. 4. Flexural strength at the age of 7 days and 28 days

\section{Water absorption}

From the test results, it is evident that the rate of entry of water through concrete is more in specimens with mineral admixtures when compared to conventional concrete. From the test results, M2 shows higher water absorption value of $40.8 \%$, which is more than the water absorption value of M0, M1 shows higher water absorption value of $41.49 \%$, which is more than the water absorption value of M0, M3 shows higher

Table 5. Water absorption at the age of 28 days

\begin{tabular}{llc}
\hline S. No & Mix & Water absorption (\%) \\
\hline 1 & M0 & 3.06 \\
2 & M1 & 5.23 \\
3 & M2 & 5.17 \\
4 & M3 & 4.7 \\
5 & M4 & 4.9 \\
6 & M5 & 3.86 \\
\hline
\end{tabular}

water absorption value of $34.8 \%$, which is more than the water absorption value of M0, M4 shows higher water absorption value of $37.5 \%$, which is more than the water absorption value of M0 and M5 shows higher water absorption value of $20.72 \%$, which is more than the water absorption value of M0. Higher water absorption by all mixes is mainly due to the presence of finer silica fume and fly ash particles. Due to higher fineness, surface area of particles will get increased. This, in turn, increases the adsorbing capacity of water molecules on the surface of those finer particles, thereby making the structure of concrete more porous leading to increased water absorption.

\section{Conclusion}

From the test results, following conclusions are derived:

a) Addition of steel slag beyond $50 \%$ has resulted in significant improvement in the compres- 


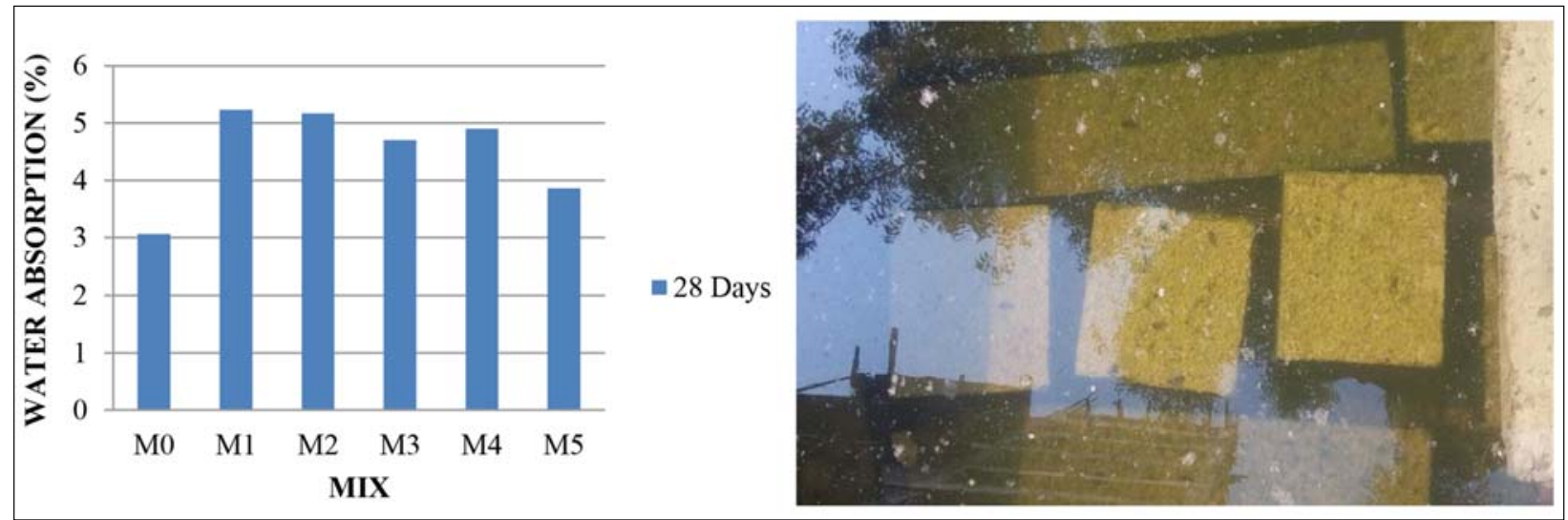

Fig. 5. Percentage of water absorption at the age of 28 days

sive strength of concrete. Addition up to $70 \%$ in M3 has also shown increase in the compressive strength of concrete. This is mainly due to its synergistic effect.

b) It could also be observed that fly ash addition along with silica fume up to $50 \%$ by weight of cement improves the pore filling ability in concrete due to the presence of such finer particles. Because of the presence of such finer particles, the rate of adsorption of water gets increased, leading to bleeding and segregation problems.

c) From the durability aspect, mix with higher percentages of silica fume and steel slag shows a higher rate of water absorption when compared to other mix combinations. This is mainly due to its finer and porous properties.

d) Replacement of cement by alternative pozzolanic materials such as fly ash and silica fume and river sand by steel slag and M-sand can be an alternative solution to reduce the scarcity of materials and in the achievement of sustainability in construction.

\section{Acknowledgements}

I would like to express my sincere gratitude to the Management, Dean (School of Environmental and Construction Technology) and Head of the Department (Civil Engineering) of Kalasalingam Academy of Research and Education for supporting me in my research work.

\section{References}

[1] Li Y., Kong F., Du R. (2009), Application of high performance concrete mixed with steel slag powder in concrete pavement. In: ICCTP2009: Critical Issues in Transportation System Planning, Development and Management, pp. 1-7. ISBN 9780784410646

[2] Doven A. G., Pekrioglu A. (2005), Material properties of high volume fly ash cement paste structural fill. J. Mater. Civ. Eng., 17(6), 686-693.

[3] Praveer S., Khan M. A., Kumar A. (2016), The effect on concrete by partial replacement of cement by silica fume: A review. International Research Journal of Engineering and Technology, 3(3), 118-121.

[4] Atis C. D. (2003), High volume fly ash concrete with high strength and low drying shrinkage. J. Mater. Civ. Eng., 15(2), 153-156.

[5] Tangchirapat W., Buranasing R., Jaturapitakku C. (2010), Use of high fineness of fly ash to improve properties of recycled aggregate concrete. J. Mater. Civ. Eng., 22(6), 565-571.

[6] Aitcin P. C., Laplante P. (1990), Long-term compressive strength of silica-fume concrete. J. Mater. Civ. Eng., 2(3), $164-170$.

[7] Monkman S., Shao Y., Shi C. (2009), Carbonated ladle slag fines for carbon uptake and sand substitute. J. Mater. Civ. Eng., 21(11), 657-665.

[8] Wright J. R., Cartwright C., Fura D., Rajabipour F. (2014), Fresh and hardened properties of concrete incorporating recycled glass as $100 \%$ sand replacement. J. Mater. Civ. Eng., 26(10), DOI: 10.1061/(ASCE)MT.1943-5533.0000979.

[9] Alaejos P., Bermudez M. A. (2011), Influence of sea water curing in standard and high-strength concrete. 23(6), 915-920.

[10] Serdar M., Biljecki I., Bjegovic D. (2017), High performance concrete incorporating locally available industrial by-products. J. Mater. Civ. Eng., 29(3), DOI: 10.1061/ (ASCE)MT.1943-5533.0001773. 